a numerous and representative corps of observers and to equip and maintain an efficient central organization in touch with all other relevant research associations, however different their methods. The observers will collect their data, which cover as wide a field as possible in order to provide sufficient cross-references to indicate the probable nature of the bias in any individual report. The scientific expert will be required not only as an observer himself but also in drawing up the plan of work, framing well-constructed hypotheses to be tested by mass-observation methods and in suggesting subjects for detailed inquiry, as well as in the interpretation of the data collected and in securing a more rigorous objectivity. The presen. tation of the results involves further problems, as not only must facts be collected over the widest possible field, but also they must be made known to the widest possible field. As soon as possible, pamphlets at present projected will deal with such questions as popular superstitions, reasons for watching birds, the meaning given to freedom, and will be based on the work of the observers. They will be followed by cheap editions of relevant scientific books, and a monthly bulletin designed for wide circulation is also contemplated. The central office and filing system is at 6 Grote's Building, Blackheath, London, S.E.3.

\section{Mould and Bacteria Killed by New Lamp}

IN the International Merchant, a monthly pamphlet -published by the Westinghouse Electric International Company at New York, a description is given of the 'Sterilamp', a gaseous conductor tube which produces very decided germicidal radiation at low temperature and low cost. It has taken nine years to develop. It is claimed that it prevents the growth of mould and bacteria on the surface of meat aged at high temperature and high humidity. It also retards the growth of mould on bakery products. Tests have shown that the lamp is useful in pasteurizing milk and beer. It is particularly useful in sterilizing conditioned air. The lamp generates radiant energy of a particular wave-length of which 90 per cent is in a region of the radiant spectrum which has been found to be strongly germicidal. It is made in lengths of 10, 20 and 30 inches, and the 20 -inch size requires only 7 watts. Of great importance when making applications to food is the fact that the unit operates at a temperature only about $5^{\circ} \mathrm{F}$. above that of the room. The lamp and auxiliary equipment is now on the market.

\section{W. Watson and Sons, Ltd.}

Messrs. W. Watson and Sons, Litd., of 313 High Holborn, London, W.C.l, have issued a booklet detailing the history of the firm in celebration of its centenary. Founded in 1837 for the manufacture of optical instruments by William Watson at 71 City Road, the business continued at this address until 1861, when it moved to 313 High Holborn, where it has since remained, and has been continuously carried on by members of the Watson family. The microscope was becoming a feature of the Watson firm in the 'seventies of last century, together with cameras and lenses, since when telescopes, X-ray equipment, cinematographs, projection lanterns and other optical instruments and apparatus have been manufactured. A pleasing portrait of William Watson, the founder, forms a frontispiece to the booklet, which concludes with a series of plates illustrating the products of the firm during the hundred years of its existence.

\section{Gift to the Royal Cancer Hospital}

Mr. A. Chester Beatty, who has recently been elected vice-president and a member of the committee of the Royal Cancer Hospital, has purchused the Freemasons' Hospital, Fulham Road, with the intention of presenting the building for conversion into the Research Institute of the Hospital, and Mr. Chester Beatty is equipping the building for this purpose in addition to presenting it to the Hospital. It is well known that the Royal Cancer Hospital has maintained a research institute for many years under the direction of Prof. E. L. Kennaway. Mr. Chester Beatty is also generously entirely re-equipping the Radio-therapeutic Department of the Royal Cancer Hospital, at a cost of some $£ 13,000$, with the latest modern high-voltage X-ray therapy apparatus embodying many new features which will prove of inestimable value, not only in the treatment of cancer but also in affording full and adequate protection to both patients and operators during the carrying out of the treatment. The Royal Cancer Hospital is a school of the University of London and, in order to encourage the study of radiology, Mr. Chester Beatty has provided a travelling scholarship which has been accepted by the senate of the University of London. The scholarship will enable a student of radiology, after obtaining the academic diplomas in medical radiology, to spend a year in one of the great radiological clinics of the United States of America.

\section{The National Health Campaign}

LAST week, November 1-6, marked the beginning of the second month of the National Health Campaign, which was recently inaugurated by the Prime Minister, and this period has been devoted to the general aspects of the campaign and has aroused considerable public interest. During November and December special emphasis is being laid on the services available for mothers and infants, while in January next the child at a later stage, the school age, will be considered, together with the value of co-operation between home and school. The medium of the campaign varies; numerous posters and leaflets have been issued, public meetings and films have been arranged, and the support of the Press and of the wireless is expected.

\section{Announcements}

Miss Jean Batren has been awarded the Gold Medal of the Royal Aero Club in recognition of her many Empire flights.

Dr. A. G. Francrs has been appointed deputy Government chemist in succession to Mr. Andrew More, who retired on November 3 . 